\section{FRI0178 CLUSTER PROFILING OF PATIENTS IN A REAL-WORLD DATA SET WITH SYSTEMIC LUPUS ERYTHEMATOSUS AND THEIR ASSOCIATED TREATMENTS}

Zahi Touma ${ }^{1}$, Ben Hoskin ${ }^{2}$, Christian Atkinson ${ }^{2}$, David Bell², Olivia Massey², Jennifer H. Lofland ${ }^{3}$, Pam Berry ${ }^{4}$, Chetan Karyekar ${ }^{3}$, Karen Costenbader ${ }^{5}$. ${ }^{1}$ University of Toronto, Toronto, Canada; ${ }^{2}$ Adelphi Real World, Cheshire, United Kingdom; ${ }^{3}$ Janssen Global Commercial Strategic Organisation, Horsham, United States of America; ${ }^{4}$ Janssen Global Services, LLC, Horsham, United States of America; ${ }^{5}$ Brigham and Women's Hospital, Boston, United States of America

Background: Previous systemic lupus erythematosus (SLE) studies have identified potential clusters of SLE clinical manifestations.

Objectives: To describe the presentation of SLE across different cohorts of patients and describe standard of care within clusters.

Methods: Cross-sectional study of 263 rheumatologists in the US and EU5. Data were collected from the Adelphi Real World 2015 Lupus Disease Specific Programme. Physicians completed patient record forms (PRFs) for the next 5 patients consulting with SLE; these patients completed patient self-completion (PSC) forms describing how SLE affected them. PRFs data include patient's characteristics and management history. PSCs focused on similar data collection, including patient reported outcome measures on the humanistic burden. Principal-component factor analysis reduced 39 unique SLE symptoms to 8 factors. These factors were used as covariates in latent class cluster analysis to provide discrete cohorts of patients. Chi-squared and Kruskal-Wallis tests compared patient outcomes across clusters.

Results: Data were extracted from 1376 PRFs. Factor analysis resulted in 8 clusters of concurrent symptoms; joint, haematological, constitutional/ mental health, skin, circulatory, cardiovascular, renal, and muscular symptoms respectively. The four-cluster solution was selected.

Cluster 1 displayed the lowest symptom burden, characterised by low skin involvement. Cluster 2 is characterised by joint and skin involvement. Cluster 3 \& 4 had a high frequency of all factors, with cardiovascular involvement high in cluster 3 and renal/constitutional involvement high in cluster 4 (table 1).

Significant between-cluster differences were observed when comparing clinical and humanistic outcomes; physician/patient satisfaction were greatest in cluster 1 (physician satisfied $94.2 \%$ vs. 2: $90.8 \%, 3: 85.2 \%, 4$ : $74.4 \%, \quad p<0.0001$; patient $94.7 \%$ vs. 2: $93.9 \%, 3: 91.5 \%, 4: 79.2 \%$, $\mathrm{p}<0.0001$ ), whilst disease progression (deteriorating slowly $2.5 \%$ vs. 2 : $12.9 \%, 3: 9.8 \%, 4: 25.5 \%, p<0.0001)$ and flaring in the last 12 months (flared $30.0 \%$ vs. 2: $54.8 \%, 3: 62.2 \%, 4: 70.8 \%, p<0.0001$ ) differed significantly with worst outcomes seen in cluster 4 .

Significant differences were also observed between clusters in relation to treatment proportions; anti-malarials (highest cluster 1: 70.5\%), biologic DMARD (highest cluster 3: 17.5\%), glucocorticoid and immunosuppressants (highest cluster 4: $85.5 \%, 74.5 \%$ ).

Conclusion: This study adds to the evidence demonstrating the heterogenous nature of SLE experienced within distinct patient clusters. Significant proportions of SLE patients experience high symptom burden and low levels of satisfaction. Additional analysis to understand limited biologic use in more severe patients is needed.

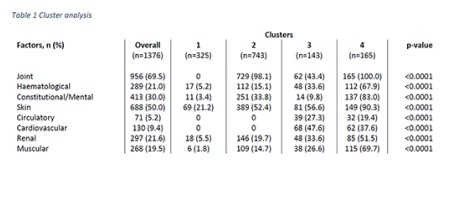

Disclosure of Interests: Zahi Touma Grant/research support from: GSK Canada, Consultant for: UBC, Pfizer, Janssen, Inc, Ben Hoskin Employee of: Adelphi, Christian Atkinson Employee of: Adelphi, David Bell Employee of: Adelphi, Olivia Massey Employee of: Adelphi Real World, Jennifer H. Lofland Employee of: Janssen Global Commercial Strategic Organization, Pam Berry Shareholder of: GSK and Janssen Global Services, Chetan Karyekar Shareholder of: J\&J, Employee of: Janssen Scientific Affairs, LLC, Abbott, BMS, Novartis, Karen Costenbader: None declared DOI: 10.1136/annrheumdis-2019-eular.4302

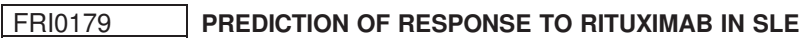 USING A VALIDATED TWO-SCORE SYSTEM FOR INTERFERON}

Adewonuola Alase $^{1}$, Zoe Wigston ${ }^{1}$, Agata Burska ${ }^{1}$, Elizabeth Hensor ${ }^{1}$, M.D. Yuzaiful M.D. Yusof ${ }^{1}$, John Reynolds ${ }^{2}$, The Masterplans Consortium ${ }^{3}$, Miriam Wittmann ${ }^{1}$, Ian N. Bruce ${ }^{2}$, Edward Vital ${ }^{1} .{ }^{1}$ Leeds Institute of Rheumatic and Musculoskeletal Medicine, Leeds, United Kingdom; ${ }^{2}$ University of Manchester, Centre for Musculoskeletal Research, Division of Musculoskeletal and Dermatological Sciences, Manchester, United Kingdom; ${ }^{3}$ University of Manchester, The MASTERPLANS project Team, Manchester, United Kingdom

Background: Rituximab (RTX) is used for resistant SLE but clinical response varies. We previously validated two interferon-stimulated gene expression scores (IFN-Score-A and IFN-Score-B) that improved prediction of clinical outcomes in SLE. IFN-Score-A included most commonly reported ISGs and predicted flares and glucocorticoid requirements. IFNScore-B included ISGs that respond to multiple IFN subtypes and predicted development of SLE in At-Risk individuals. Diagnosis of SLE was associated with both scores, while only IFN-Score-B was elevated in RA The British Society for Rheumatology Biologics Registry (BILAG-BR) collects samples for RTX-treated patients in the UK. MASTERPLANS is a consortium to identify predictors of drug response.

Objectives: To investigate whether IFN-Score-A and IFN-Score-B predict BILAG response to RTX at 6 months.

Methods: This is a preliminary analysis of the first RTX-treated patients in the BILAG-BR with complete data. Patients were recruited if they were starting a first cycle of RTX for active SLE (BILAG A or 2xBILAG B) despite previous cyclophosphamide or mycophenolate mofetil. Disease activity was measured using BILAG-2004. Clinical response was defined as improvement by $>=1$ grade in active BILAG-2004 systems with no worsening in other systems. Whole blood was collected into TEMPUS tubes and RNA extracted. IFN-Scores were measured using a custom Taqman array as previously described [El Sherbiny et al., 2018]. Multivariate logistic regression was used to test IFN-Scores and baseline clinical covariates as predictors of BILAG response at 6 months.

Results: Samples were available from 147 patients, of whom 84 had complete baseline and 6 month clinical data available and were included in this analysis. $40 / 84(47.6 \%)$ patients had BILAG response at 6 months. In univariate and multivariate analysis, high IFN-Score-B expression was significantly associated with clinical response (see table 1).

\begin{tabular}{lcccc}
\hline Predictor & $\begin{array}{c}\text { Non- } \\
\text { responders }\end{array}$ & Responders & Univariable OR (95\% & Multivariable OR (95\% \\
Cl)
\end{tabular}


Conclusion: This preliminary analysis suggests that assessment of IFN activity has a role in predicting response to RTX. A novel IFN score (Score B) was more predictive than classic ISGs (Score A). These results add to a body of work showing that IFN-Score-B predicts clinically significant outcomes independently of overall IFN activity. Future work will analyse this biomarker in a larger cohort of patients and integrate with other putative clinical and biological predictors of response.

\section{REFERENCE:}

[1] El-Sherbiny, Y. M.... E. M. Vital (2018). Sci. Rep. 8: 5793

Acknowledgement: We would like to thank the Medical Research Council, National Institute of Health Research, UK for funding the MASTERPLANS project.

Disclosure of Interests: Adewonuola Alase: None declared, Zoe Wigston: None declared, Agata Burska: None declared, Elizabeth Hensor: None declared, Md Yuzaiful Md Yusof: None declared, John Reynolds: None declared, The Masterplans Consortium: None declared, Miriam Wittmann Consultant for: consultancy honoraria from Abbvie, Celgene, Janssen, L'Oreal, Novartis and Pfizer, lan N. Bruce Grant/research support from: Genzyme Sanofi, GlaxoSmithKline, Consultant for: AstraZeneca, Eli Lilly, GlaxoSmithKline, ILTOO Pharma, Medlmmune, Merck Serono, Speakers bureau: GlaxoSmithKline, UCB Pharma, Edward Vital Grant/research support from: He has received honoraria and research grant support from Roche, GSK and AstraZeneca.

DOI: 10.1136/annrheumdis-2019-eular.5750

\section{FRI0180 OFF-LABEL USE OF RITUXIMAB IN RHEUMATIC DISEASES, A SWISS TERTIARY CENTRE EXPERIENCE}

Alexandre Dumusc, Thomas Huegle, Pascal Zufferey. University Hospital Lausanne (CHUV), Rheumatology, Lausanne, Switzerland

Background: Rituximab (RTX), a monoclonal antibody targeting CD20, is licenced for the treatment of rheumatoid arthritis (RA) for many years and more recently for ANCA-associated vasculitis. RTX is frequently used off-label to treat other auto-immune diseases (AID), especially connective tissue diseases (CTD). There are no published data about off-label use of RTX in AID in Switzerland.

Objectives: To describe off-label use of RTX in a real-life setting, when treating AID.

Methods: Retrospective cohort study of all patients treated with RTX in the Rheumatology Department between 2005 and 2017. Clinical efficacy of RTX after 12 and 24 months of treatment was evaluated with a semiquantitative scale (no response (NR), partial (PR) and complete response (CR)). RTX discontinuation rate was also analysed using Kaplan-Meier method and log rank test to evaluate the difference between survival curves. Adverse events $(A E)$, serious $A E$ (SAE) were included in the safety analysis. Occurrences of hypogammaglobulinemia and anti-rituximab antibodies (ADA) were also reported.

Results: 178 patients treated with RTX could be identified: $28 \%$ for CTD, $63 \%$ for RA and $10 \%$ for other AID.

Rituximab was used off-label in $73 \%$ of the patients according to official Swiss indications. No significant differences in terms of clinical response were observed in off-label indication after 12 months (NR: 15\%/13\%, PR:48\%/52\%, CR:37\%/35\%, $n=108 / 31)$ and 24 months (NR:13\%/9\%, PR:37\%/35\%, CR: $51 \% / 57 \%, n=79 / 23$ ) of treatment when compared with prescriptions following official Swiss indications, respectively. RTX discontinuation rate $(\mathrm{HR} 1.0395 \% \mathrm{Cl} 0.71-1.49)$ was also similar between both groups.

Clinical response after RTX treatment did not differ significantly between patients with CTD and RA after 12 months (NR:10\%/12\%, PR:50\%/52\%, CR: $40 \% / 36 \%, \quad n=42 / n=84$ ) and 24 months (NR:7\%/9\%, PR:32\%/44\%, CR: $61 \% / 47 \%, n=28 / n=64)$, respectively. Detailed results are available in Table 1. Survival curves of rituximab treatment from CTD group closely matched that from RA group (HR $0.9695 \% \mathrm{Cl} 0.65-1.44)$. Causes of RTX treatment discontinuation in patients with CTD $(n=27)$ and RA $(n=72)$ consisted of lack of efficiency $(63 \% / 56 \%)$, adverse event $(19 \%)$ $35 \%$ ) and remission $(19 \% / 10 \%)$, respectively.

SAE $(n=113)$ occurred in $33 \%$ of the patients and consisted mainly of infectious SAE (43\%) and perfusion-related $\mathrm{AE}(6 \%) .6$ patients died during RTX treatment. Low IgG levels were observed in $34 \%(50 / 149)$ of the patients graded as mild $(20 \%)$, moderate $(11 \%)$ or severe $(3 \%)$. The nadir of IgG levels occurred after 4.5(3.5) years (mean (SD)) of RTX treatment. ADA were observed in $6 / 51$ patients.
Conclusion: Off-label prescription of rituximab to treat AID was frequent. RTX discontinuation rate was comparable in patients treated for CTD and $\mathrm{RA}$ in our population.

\section{Table 1}

\begin{tabular}{|c|c|c|c|c|c|c|}
\hline & $\begin{array}{c}\text { Off-label } \\
\text { prescription }\end{array}$ & $\begin{array}{l}\text { Partial or } \\
\text { complete } \\
\text { response } \\
\text { after } 12\end{array}$ & $\begin{array}{l}\text { Partial or } \\
\text { complete } \\
\text { response } \\
\text { after } 24\end{array}$ & $\begin{array}{r}\mathrm{F} \\
\text { disco } \\
(95 \%\end{array}$ & $\begin{array}{l}\text { ituxima } \\
\text { tinuatic } \\
\text { Cl), all c } \\
\text { at : }\end{array}$ & n rate \\
\hline & n (\%) & $\mathrm{n}=139(\%)$ & $n=102(\%)$ & $\begin{array}{c}1 \\
\text { year }\end{array}$ & $\begin{array}{c}2 \\
\text { years }\end{array}$ & $\begin{array}{c}4 \\
\text { years }\end{array}$ \\
\hline $\begin{array}{l}\text { Connective } \\
\text { tissue disease } \\
(n=49)\end{array}$ & 49/49 (100) & $38 / 42(90)$ & $26 / 28$ (93) & $\begin{array}{c}0.23 \\
(0.13- \\
0.37)\end{array}$ & $\begin{array}{c}0.40 \\
(0.27- \\
0.55)\end{array}$ & $\begin{array}{r}0.56 \\
(0.42- \\
0.71)\end{array}$ \\
\hline $\begin{array}{l}\text { Overlap } \\
\text { syndrome } \\
(n=14)\end{array}$ & & $12 / 12(100)$ & 9/9 (100) & & & \\
\hline $\begin{array}{l}\text { Systemic lupus } \\
\text { erythematosus } \\
(\mathrm{n}=12)\end{array}$ & & $8 / 10(80)$ & $7 / 8$ (88) & & & \\
\hline UCTD $(n=8)$ & & 4/6 (67) & $2 / 2(100)$ & & & \\
\hline $\begin{array}{l}\text { Sjögren's } \\
\text { syndrome }(n=6)\end{array}$ & & $6 / 6(100)$ & $4 / 4(100)$ & & & \\
\hline $\begin{array}{l}\text { Dermato-, } \\
\text { polymyositis } \\
(n=5)\end{array}$ & & $5 / 5(100)$ & $2 / 3(67)$ & & & \\
\hline MCTD $(n=3)$ & & $2 / 2(100)$ & $1 / 1(100)$ & & & \\
\hline $\begin{array}{l}\text { Systemic } \\
\text { sclerosis }(n=1)\end{array}$ & & $1 / 1(100)$ & $1 / 1(100)$ & & & \\
\hline $\begin{array}{l}\text { Rheumatoid } \\
\text { arthritis }(n=112)\end{array}$ & 66/112 (59) & 74/84 (88) & $58 / 64(91)$ & $\begin{array}{c}0.27 \\
(0.20- \\
0.36)\end{array}$ & $\begin{array}{c}0.35 \\
(0.27- \\
0.44)\end{array}$ & $\begin{array}{r}0.55 \\
(0.46- \\
0.65)\end{array}$ \\
\hline $\begin{array}{l}\text { Other auto- } \\
\text { immune } \\
\text { diseases }(n=17)\end{array}$ & 15/17 (88) & $7 / 13(54)$ & $6 / 10(60)$ & $\begin{array}{r}0.35 \\
(0.18- \\
0.62)\end{array}$ & $\begin{array}{r}0.76 \\
(0.55- \\
0.93)\end{array}$ & - \\
\hline
\end{tabular}

RTX: rituximab; AE: adverse event, MCTD: Mixed connective tissue disease; UCTD: Undifferentiated connective tissue disease.

*off-label prescription according to Swiss Agency for Therapeutic Products (Swissmedic)

Disclosure of Interests: Alexandre Dumusc: None declared, Thomas Huegle Grant/research support from: AbbVie, Lilly, Novartis and Pfizer, Speakers bureau: AbbVie, Lilly, Novartis and Pfizer, Pascal Zufferey: None declared

DOI: 10.1136/annrheumdis-2019-eular.6923

\section{FRI0181 THE PLUTO STUDY: INTRAVENOUS BELIMUMAB IN CHILDREN WITH SYSTEMIC LUPUS ERYTHEMATOSUS}

Nicolino Ruperto ${ }^{1}$, Carlos Abud-Mendoza ${ }^{1}$, Diego O. Viola ${ }^{1}$, Inmaculada Calvo ${ }^{1}$, Deborah M. Levy ${ }^{2}$, Julia Calderon Gallegos ${ }^{1}$, Manuel Ferrandiz ${ }^{1}$, Vyacheslav Chasnyk ${ }^{1}$, Vladimir Keltsev¹, Jordi Anton ${ }^{1}$, Maria Gastanaga ${ }^{1}$, Michael Shishov ${ }^{2}$, Alina Boteanu ${ }^{1}$, Michael Henrickson ${ }^{2}$, Damon Bass ${ }^{3}$, Ken Clark ${ }^{4}$, Anne Hammer ${ }^{3}$, Beulah $\mathrm{Ji}^{4}$, Antonio Nino ${ }^{5}$, David Roth ${ }^{3}$ Herbert Struemper ${ }^{6}$, Mei-Lun Wang ${ }^{5}$, Alberto Martini ${ }^{1}$, Daniel J Lovell ${ }^{2}$ Hermine Brunner ${ }^{2}{ }^{1}$ Member of PRINTO, Istituto Gaslini, Genoa, Italy; ${ }^{2}$ Member of PRCSG, Cincinnati, United States of America; ${ }^{3}$ GSK, Philadelphia, United States of America; ${ }^{4}$ GSK, Stevenage, United Kingdom; ${ }^{5}$ GSK, Collegeville, United Kingdom; ${ }^{6}$ GSK, Research Triangle Park, United States of America

Background: Belimumab (BEL), a monoclonal antibody targeting the $\mathrm{B}$ lymphocyte stimulator, is approved in adults with active systemic lupus erythematosus (SLE). This is the first clinical trial of belimumab in pedia tric patients with childhood-onset SLE (cSLE).

Objectives: PLUTO, a Phase 2, randomised, double-blind tria (BEL114055; NCT01649765), evaluated the efficacy, safety and pharmacokinetics (PK) of intravenous (IV) BEL vs placebo (PBO), plus standard of care (SoC), in cSLE.

Methods: Patients with cSLE 5-17 years of age were randomised to BEL $10 \mathrm{mg} / \mathrm{kg}$ IV or PBO every 4 weeks, plus SoC. Primary endpoint: SRI4 at Week 52. Major secondary endpoints: PRINTO/ACR 30 and 50 cSLE evaluation criteria for improvement at Week 52; cSLE core response variables at Week 52; and sustained SRI4 and ParentGA (patient well-being) responses (Weeks 44-52). Other endpoints: components of SRI4 at Week 52; and frequency of severe flares using the 